\title{
MESTRADOS PROFISSIONAIS: CARACTERÍSTICAS, ESPECIFICIDADES, DIFERENÇAS E RELATOS DE SUCESSO
}

\author{
VOCATIONAL MASTER'S: CHARACTERISTICS, SPECIFICITIES, DIFFERENCES \\ AND SUCCESS STORIES
}

\author{
Recebido em: 01/10/2012 - Aprovado em: 23/01/2013 \\ Avaliado pelo sistema double blind review \\ Editora Científica: Manolita Correia Lima
}

\section{ROBERTO BRAZILEIRO PAIXÃO robertobrazileiro@gmail.com ADRIANO LEAL BRUNI \\ UNIVERSIDADE FEDERAL DA BAHIA}

\begin{abstract}
RESUMO
O surgimento dos mestrados profissionais (MPs) corresponde a uma busca pela aproximação da produção acadêmica às práticas laborais, ou seja, um olhar voltado para as necessidades do mercado de trabalho. Nesse sentido, este artigo objetiva apresentar as características distintas dos MPs, diferenciando-o das demais modalidades de cursos da pós-graduação brasileira, ao mesmo tempo em que busca evidências na literatura de casos de sucesso, na tentativa de aproximar a academia do ambiente profissional. Para tanto, é construída uma linha discursiva que perpassa a evolução da legislação, as características específicas, a tensão existente entre as modalidades acadêmica e profissional, as semelhanças e diferenças com os cursos lato sensu e relatos de casos de sucesso. Conclui-se o artigo ressaltando a necessidade de maior aprendizado sobre esta modalidade de curso, de forma a entender suas especificidades e relações com os demais programas de formação, notadamente os cursos de pós-graduação.
\end{abstract}

Palavras-chave: mestrados profissionais; características; programas.

\begin{abstract}
The emergence of Brazilian MP (Vocational Master's) degrees corresponds to the attempt to bring academic production more in line with working practices, that is, to see things from the point of view of the needs of the employment market. Accordingly, this paper presents the MP's characteristics, differentiating it from other forms of post-graduate courses in Brazil while seeking evidence in the literature of successful cases representing attempts to bring the academy's professional environment closer to the working one. A discursive line that runs through the development of legislation, specific features, the tension between the academic and professional axes, the similarities and differences with post graduate non-degree courses, and reports of success was therefore laid out. The paper concludes highlighting the need for further analysis about these courses in order to understand their characteristics and relationships with other training programs, especially post graduate courses.

Keywords: vocational master's; characteristics; programs.
\end{abstract}




\section{INTRODUÇÃO}

A expansão das instituições de ensino superior, notadamente as federais, bem como do sistema nacional de pós-graduação, adotando a concepção do modelo linear (concepção a qual insere a mudança tecnológica como resultado de uma sequência articulada de estágios, onde os conhecimentos da pesquisa básica levariam a processos de invenção, que seguiriam as atividades de pesquisa aplicada e o desenvolvimento tecnológico, e que culminariam com a introdução de processos ou produtos comercializáveis) serviu de impulso para as atividades de pesquisa. A pós-graduação foi criada no Brasil com a função de qualificar recursos humanos e também de produzir conhecimento científico, que, aliada à visão humboldtiana de autonomia, buscava superar a dependência em relação aos países centrais (MOREIRA; VELHO, 2008).

Apesar de não se caracterizar fundamentalmente como um sistema típico alemão, com forte ênfase na pesquisa básica, dada à também influente corrente utilitária de base norte-americana, um estudo apresentado por Krieger e Galembeck (1996) sobre a pesquisa brasileira em meados dos anos 1990, permitiu observar que existe um distanciamento entre o que os cientistas pesquisam e a realidade empresarial.

Apesar do distanciamento em relação às atividades empresariais, Schwartzman (2002) argumenta que boa parte das pesquisas no Brasil, praticamente sempre esteve vinculada aos interesses do Estado; porém, por se desenvolverem nos moldes institucionais e acadêmicos da pesquisa básica, raramente conduziram a aplicações de fato. Para este autor, os cientistas sempre buscaram explicações racionais para justificarem as verbas para a pesquisa desinteressada. O que não é tão facilmente percebido é que, independentemente das intenções, a transformação da pesquisa, básica ou aplicada, em resultados efetivos depende de arranjos institucionais, o que dificilmente ocorre no ambiente universitário brasileiro.

O sistema de pós-graduação brasileiro é dividido em cursos stricto sensu e cursos lato sensu. Os primeiros correspondem aos cursos de mestrado (acadêmico e profissional) e doutorado, enquanto os segundos referem-se aos 
cursos de especialização (BRASIL, 2004). A pós-graduação obteve pleno êxito como um sistema concebido para formar professores e pesquisadores para as universidades. Porém, dois ambientes parecem ter ficado inexplorados: as empresas, que necessitam de profissionais com formação de alto nível, além da graduação; e as instituições de ensino que, muitas vezes, precisam de um professor com perfil diferente do acadêmico-pesquisador (CASTRO, 2005).

Os primeiros cursos de mestrado profissional (MPs) datam da década de 1990 e representam o reconhecimento da necessidade e uma alternativa em relação à formação de professores e pesquisadores, ou seja, um formato que orienta o ensino para a aplicação, para a prática (FISCHER, 2005). Melo e Oliveira (2005) destacam que o surgimento dos MPs corresponde a uma busca pela aproximação da produção acadêmica às práticas laborais, ou seja, um olhar voltado para as necessidades do mercado de trabalho.

Em outras palavras, o mestrado profissional poderia ser um caminho para o alcance de resultados efetivos no ambiente profissional. Nesse sentido, este artigo objetiva apresentar as características distintas dos MPs, diferenciando-os das demais modalidades de cursos da pós-graduação brasileira, ao mesmo tempo em que busca evidências na literatura de casos de sucesso na tentativa de aproximar a academia do ambiente profissional, ou seja, visualizar a pesquisa além do modelo linear. 


\section{OS MESTRADOS PROFISSIONAIS}

De acordo com o Parecer nº.977/1965, a pós-graduação stricto sensu é composta de dois níveis, o mestrado e o doutorado, sendo que, mesmo hierarquizados, a conquista do doutorado não exige a obtenção prévia do mestrado. O objetivo do doutorado é o de desenvolver a capacidade ampla de pesquisa; para tanto, o candidato deverá defender uma tese que apresente uma real contribuição para o conhecimento de um tema. Para o mestrado exige-se a defesa de uma dissertação, que deve representar a capacidade do candidato de sistematizar e dominar um determinado tema (BRASIL, 1965).

Ainda com relação ao Parecer n”. 977/1965, o mesmo deixa claro que "o mestrado tanto pode ser de pesquisa como profissional” (BRASIL, I965, p. o6). Este foi o primeiro documento formal, em termos de legislação, que suportou a existência dos mestrados profissionais (FISCHER, 2003).

\section{A EVOLUÇÃO DA LEGISLAÇÃO SOBRE OS MESTRADOS PROFISSIONAIS}

O Parecer $\mathrm{n}^{\circ}$. 977/1965, mesmo citando a possibilidade de um mestrado profissional, não dá maiores esclarecimentos acerca do mestrado profissional. Foi apenas em 1995 que um novo documento especificou algumas características dos MPs.

A Portaria $n^{\circ} .47$ de 1995 (BRASIL, I995) determinou a implantação na Capes de procedimentos apropriados para a recomendação, acompanhamento e avaliação dos cursos de mestrado profissional. Alguns pontos da Portaria merecem ser destacados. Primeiro, a orientação para que os orientadores dos alunos possuíssem o título de doutor ou qualificação profissional inquestionável, podendo estes últimos atuar como coorientadores. A quantidade de professores não doutores, profissionais altamente qualificados, deveria constituir uma parte restrita do corpo docente, além da necessidade de sua escolha ser justificada, documentada e controlada. Ademais, a carga horária destes professores, apesar de não precisar ser integral, deveria ser compatível com a necessidade do curso. Segundo, os cursos deveriam articular as atividades de ensino com a aplicação das pesquisas, de forma 
flexível e diferenciada. Um terceiro ponto referia-se ao trabalho formal de finalização do curso. Assumiu-se a possibilidade de outras formas de trabalho, além da tradicional dissertação, como: projeto, análise de casos, produção artística, entre outros. O credenciamento inicial seria exclusivo de programas de pós-graduação já consolidados ou de instituições sem tradição na pós-graduação, mas que fossem altamente qualificadas. As avaliações da Capes seriam anuais, com grupos interdisciplinares e a produção técnicoprofissional deveria ser valorizada. E, por fim, enfatizou a questão do autofinanciamento, cabendo aos cursos a busca de convênios para patrocinálos, exceto nos segmentos de mercado onde isto seja operacionalmente difícil. Nestes casos, a Capes manteria as habituais formas de apoio.

Barros, Valentim e Melo (2005) asseveram que a publicação dessa portaria de 1995 talvez tenha sido o ato mais arrojado para o direcionamento de uma demanda latente, ao referir-se aos mestrados profissionais, os quais tinham poucas chances de aceitação de suas propostas frente ao modelo de avaliação do mestrado acadêmico, tido como vigente.

Em 1998 foi emitida uma nova portaria, a de $n^{\circ}$. 80, que dispôs sobre o reconhecimento dos MPs (BRASIL, 1998). De acordo com esta portaria, para ser classificado como mestrado profissional o curso deveria: a) possuir uma estrutura curricular que articulasse o ensino com a aplicação profissional; b) ter uma duração mínima de um ano; c) ter no seu quadro docente a maioria de doutores, porém com uma parcela a ser constituída de profissionais de qualificação e experiência inquestionáveis; d) ter condições de trabalho e carga horária compatíveis com o curso, sendo admitido o regime de dedicação parcial; e e) ter um trabalho final de curso, mantendo as mesmas opções da portaria anterior, ressaltando, porém, a necessidade de o aluno demonstrar a capacidade de expressar-se lucidamente sobre o tema. Esta portaria também reafirma a avaliação de competência da Capes, que passa a ser feita em conjunto com os demais programas, e a vocação para o autofinanciamento. Vale ressaltar que a produção técnicoprofissional mantém-se valorizada. Ademais, a portaria continha abertura para uma possível alteração no curso, passando o mesmo de acadêmico para profissional. 
No ano de 2009, foram publicadas outras duas portarias acerca dos MPs, a Portaria $\mathrm{n}^{\circ}$. 07, de 22 de junho de 2009, e a Portaria n ${ }^{\circ}$. 17, de 28 de dezembro de 2009. A segunda mantém os mesmos pontos da primeira, com a adição de alguns parâmetros para o acompanhamento e avaliação trienal dos cursos.

A Portaria $\mathrm{n}^{\circ} .07 / 2009$ definiu conceitualmente os MPs, o órgão regulador, os objetivos dos MPs, os conteúdos básicos de uma proposta e dispôs sobre a avaliação (BRASIL, 2009a). De acordo com a mesma, o mestrado profissional é caracterizado como um curso de pós-graduação stricto sensu que possibilita: a) a capacitação voltada para a prática profissional, de forma a habilitar o profissional concluinte a atuar em atividades técnicocientíficas e de inovação, por meio da incorporação do método científico; b) a formação de profissionais qualificados pela apropriação e aplicação do conhecimento em conjunto com o rigor metodológico e os fundamentos científicos; e c) a incorporação e atualização dos avanços científicos e tecnológicos de forma aplicada tendo como foco a gestão, a produção técnico-científica aplicada e aperfeiçoamentos tecnológicos voltados para a solução de problemas específicos. Com base nessa definição, destacamse os objetivos dos MPs identificados na portaria, a saber: a) capacitar profissionais para a prática profissional, visando atender a demandas sociais, organizacionais ou profissionais e do mercado de trabalho; b) transferir conhecimento para a sociedade, visando o desenvolvimento nacional, regional ou local; c) articular a academia com as entidades demandantes, com fins a melhorar a eficácia e a eficiência das mesmas; e d) contribuir para agregar competitividade e produtividade para as organizações públicas e privadas. A Capes ficou responsável por regular a oferta dos MPs por meio de chamadas públicas. Cursos com duração temporária são previstos como forma de atender a situações relevantes, porém esporádicas e específicas. Além disso, a portaria deixa claro que o título de mestre obtido nos cursos de MPs tem validade nacional equivalente ao acadêmico, desde que obtidos em programas reconhecidos e avaliados pela Capes.

Com relação à proposta de curso de mestrado profissional, a Portaria ${ }^{\circ}$. 07/2009 esclarece que a mesma deve: a) ser objetiva em termos de estrutura curricular, com ênfase na articulação do conhecimento, do domínio da 
metodologia e aplicação orientada para o campo de atuação profissional de vinculação do curso; b) ser compatível com a formação em no mínimo um ano e no máximo dois; c) possibilitar, de forma justificada e coerente, atividades curriculares das ciências sociais aplicadas, como legislação, comunicação, administração, ciência política e ética; d) adequar a proposta ao perfil dos candidatos ao curso; e) possuir equilíbrio do corpo docente, entre professores doutores e profissionais e técnicos com experiência em pesquisa aplicada e inovação; f) ter normas claras a respeito da seleção dos professores orientadores; g) ter carga horária docente compatível com o curso, sendo admitido o regime de dedicação parcial; h) prever a defesa do trabalho final de curso, de forma a demonstrar que o aluno possui plena capacidade de expressar-se sobre seu objeto de estudo, como atividade obrigatória.

A atividade obrigatória de apresentação e defesa de um trabalho final tem seu escopo de possibilidades ampliado em relação às legislações anteriores, podendo este ser: uma dissertação nos moldes tradicionais; uma revisão sistemática, porém profunda, da literatura; artigo; patente; registros de propriedade intelectual; projetos técnicos; publicações tecnológicas; desenvolvimento de aplicativos, de materiais didáticos e instrucionais e de produtos, processos e técnicas; produção de programas de mídia; editoria; composições; concertos; relatórios finais de pesquisa; softwares; estudos de caso; relatório técnico com regras de sigilo; manual de operação técnica; protocolo experimental ou de aplicação em serviços; proposta de intervenção em procedimentos clínicos ou de serviço pertinente; projeto de aplicação ou adequação tecnológica; protótipos para desenvolvimento ou produção de instrumentos, equipamentos e kits; projetos de inovação tecnológica; produção artística; além de outros, desde que aprovados previamente pela Capes.

$\mathrm{E}$, com relação à avaliação, os mestrados profissionais também devem ser avaliados anualmente com estabelecimento de critério trienal e as notas dos cursos variam de i a 5, sendo 3 o mínimo para aprovação pela Capes. O parecer não prevê as notas 6 e 7 para os MPs. Ademais, pode-se destacar a orientação para que sejam utilizadas na avaliação fichas próprias 
e diferenciadas dos mestrados acadêmicos, além do fato de as comissões específicas serem formadas por professores doutores e profissionais e técnicos do ambiente profissional.

A Portaria $\mathrm{n}^{\circ}$. I7, de 28 de dezembro de 2009 (BRASIL, 2009b), que substituiu a de $\mathrm{n}^{\circ}$. 07 do mesmo ano, reapresenta os pontos citados além de trazer duas outras orientações. Uma delas refere-se à disponibilização de bolsas de estudos, que não são previstas, exceto em áreas priorizadas pelo governo. A segunda refere-se a uma complementação sobre a avaliação dos cursos, indicando como parâmetros de acompanhamento e avaliação dos mesmos alguns indicadores.

Quadro I Resumo da evolução dos principais pontos da legislação sobre os MPs

\begin{tabular}{|ll|}
\hline Parecer no. 977/1965 & Identificação dos cursos de cunho profissional \\
\hline Portaria no. 47/1995 & $\begin{array}{l}\text { Quadro docente misto, interlocução com o meio empresarial, possibi- } \\
\text { lidade de outros formatos de trabalho final de curso e vocação para o } \\
\text { autofinanciamento }\end{array}$ \\
\hline Portaria no. 80/1998 & $\begin{array}{l}\text { Regime de dedicação parcial para docentes, processo de avaliação } \\
\text { integrado aos demais programas }\end{array}$ \\
\hline Portaria no. 07/2009 & $\begin{array}{l}\text { Conceituação, objetivos, conteúdo das propostas, novas definições } \\
\text { para o trabalho final de curso e avaliação integrada aos demais progra- } \\
\text { mas, mas com fichas e comissões específicas }\end{array}$ \\
\hline Portaria no. 17/2009 & $\begin{array}{l}\text { Não concessão de bolsas de estudo (exceto para áreas priorizadas) e } \\
\text { definição de parâmetros e indicadores para avaliação dos cursos }\end{array}$ \\
\hline
\end{tabular}

\section{CARACTERÍSTICAS DOS MESTRADOS PROFISSIONAIS}

No Brasil, durante muito tempo, houve a separação rígida entre os cursos profissionais e acadêmicos, separação esta de fato, pois os cursos profissionais no âmbito da pós-graduação stricto sensu já estavam previstos na legislação. Os que desejassem participar de um curso profissional deveriam procurar os cursos de especialização, ou cursos de pós-graduação lato sensu, caracterizados por um menor prestígio acadêmico e social (BERTERO, 1998).

A portaria $n^{\circ} .47 / 1995$ veio a público num momento muito específico para a pós-graduação brasileira. Menandro (2010) discorre que dois pontos são importantes na contextualização do início dos mestrados profissionais: a) o 
crescimento dos programas de doutorado não era muito significativo, o que valorizava o único tipo de mestrado existente; e b) as avaliações dos cursos por parte da Capes estavam ficando mais específicas e fundamentadas principalmente na produção científica publicada. Assim, os MPs já começaram tendo uma comparação com um curso plenamente estabelecido e gerando uma série de controvérsias a respeito da sua avaliação.

Os cursos de mestrado acadêmico e profissional possuem natureza qualitativamente diferente. O curso de mestrado acadêmico visa à formação do pesquisador e constitui-se, apesar de não formalmente, num passo para a obtenção do grau de doutor. Trata-se de um curso de caráter propedêutico e de relevância para o estágio de desenvolvimento do país. Já o curso de mestrado profissional caracteriza-se por formar alunos para o mercado de trabalho, que não o acadêmico. Os MPs são cursos voltados para a aplicação prática, em um campo profissional devidamente definido, visando o uso de conhecimentos e métodos científicos atualizados em situações e problemas reais e mais imediatos, tendo caráter terminal (FISCHER, 2003).

Para Mattos (I997, p. I54), os MPs são cursos dirigidos para a clientela do meio profissional, não acadêmicos ou universitários, que desejem uma pós-graduação stricto sensu. São cursos que exigem defesa de dissertação perante uma banca, não monografias de menor rigor acadêmico, e onde “[...] a qualificação de 'científico’ como critério é denominador comum para a discussão".

Andrade, D’Ávila e Oliveira (2004) asseveram que os mestrados profissionais têm como características a articulação entre pesquisa e a produção científica e técnica, um corpo docente qualificado e com experiência gerencial, além de desenhos curriculares e estratégias de ensino-aprendizagem inovadoras, que incorporem as experiências profissionais dos alunos e as demandas da sociedade. Estas características representam um grande desafio, pois exigem compromisso crítico-reflexivo, qualidade de ensino, constante confronto teoria-prática e níveis crescentes de interdisciplinaridade.

O mestrado profissional constitui-se numa oportunidade de aproximar as demandas sociais e profissionais da universidade. Suas dissertações devem ser voltadas para a prática, partindo de conceitos e teorias. Assim, 
são capazes de encurtar o tempo entre uma investigação e sua aplicação ou USO (PIQUET; LEAL; TERRA, 2005).

A inserção dos MPs na sociedade representa maior aproximação e articulação da universidade com a realidade social. A identidade dos MPs consiste justamente nessa capacidade de obter conteúdos teóricometodológicos vinculados à aplicação prática. É uma forma de articular a universidade com setores da sociedade, de forma a criar mecanismos de aplicabilidade dos resultados das pesquisas (NEGRET, 2008).

Quelhas, Faria Filho e França (2005) asseveram que os mestrados profissionais são, por força de legislação, cursos de pós-graduação stricto sensu e como tal, devem obedecer aos procedimentos típicos desta modalidade, incluindo aí as atividades de pesquisas a serem realizadas no âmbito das disciplinas e também na dissertação. Esta orientação visa formar um profissional capacitado para pesquisa, desenvolvimento e inovação, além de ter efeito multiplicador, uma vez que os conhecimentos são repassados para outros profissionais no seu campo profissional. Para estes autores, o mestrado profissional deve propor novas soluções para os problemas específicos de um campo profissional, o que requer um conhecimento teórico das soluções existentes.

As principais características de um mestrado profissional devem ser a proximidade entre a universidade e as empresas, além do desenvolvimento de pesquisas voltadas para a inovação, cuja aplicação se dê no médio ou curto prazo (AGOPYAN; OLIVEIRA, 2005). Estes autores, ao comentarem sobre os MPs em Engenharia, argumentam que é necessário que os problemas da área sejam trazidos do ambiente profissional para o seio da universidade. Isso inclui a colaboração por meio de seus profissionais, que devem ministrar aulas e coorientarem os alunos. As pesquisas devem ser realizadas na universidade e também nas instalações das empresas, ou seja, a identificação da empresa e seu envolvimento com o curso devem ser mapeados desde a sua concepção, tornando essa empresa um agente tão importante quanto a universidade.

Para Feltes e Baltar (2005), os mestrados profissionais promovem o encurtamento da distância entre as universidades e outros setores 
da economia, notadamente as empresas. O mestrado profissional pode representar um elo entre a cadeia produtiva regional e o ambiente técnicocientífico. As organizações podem buscar nos MPs profissionais aptos a formular e propor soluções para novos problemas, os quais não são resolvidos, a priori, apenas com profissionais cuja formação se limita à graduação ou especialização. Ao promover o desenvolvimento dos negócios nos quais os alunos estão inseridos, os MPs terminam por promover também o desenvolvimento socioeconômico da comunidade regional.

Outra forma de aproximação da universidade ao ambiente profissional está presente nos MPs, por intermédio do corpo docente. Assim como previsto inicialmente na Portaria $\mathrm{n}^{\circ}$. 47/1995 e em todas as subsequentes, o corpo docente destes cursos é formado por professores doutores e por profissionais do mercado, os quais podem atuar em tempo parcial e que trazem consigo a experiência do cotidiano das organizações, com suas demandas e problemas (VASCONCELOS; VASCONCELOS, 20IO). A incorporação dos professores profissionais ou executivos professores está calcada na valorização do saber prático, independentemente da titulação do indivíduo. Assim, um mestrado profissional deve ter tantos professores doutores quantos forem necessários, da mesma forma que deve ter um número de professores não doutores suficiente para contribuir com atividades voltadas para a experiência (FISCHER, 2005).

Ainda com relação à incorporação de profissionais no corpo docente, Menandro (20I0) ressalta que, na maioria das vezes, lhes falta titulação, sobra experiência profissional, consolidada pela execução de projetos empresariais e também pela realização de outros cursos.

Os mestrados profissionais representam uma renovação também para as instituições que os hospedam. Isso porque são programas de dedicação parcial, ou seja, o aluno não precisa desvincular-se do seu trabalho para fazer o mestrado e isto, por si só, representa um elo entre a universidade e as organizações; grande parte das empresas inclusive paga as taxas escolares, o que também representa um elo; e, também por conta da dependência, por parte das instituições de ensino, dos recursos do setor privado, principalmente após a década de 1990 (WOOD JR.; PAES DE PAULA, 2004). 
Dada a amplitude dos MPs, Fischer (2005) apresenta os cursos, basicamente, como três modelos. Um caso corresponde aos mestrados profissionais generalistas, típico da área de Administração, cujo objetivo principal seria o de formar profissionais qualificados em nível estratégico. Como exemplos são citados os cursos de Administração da UfBA e da UFRGS, além dos programas da FGV (EAESP e EBAPE). Outro corresponde aos cursos focalizados, presentes nas áreas de Engenharia e Odontologia ou em áreas com viés tecnológico e de políticas públicas mais fortes. Seu objetivo é formar profissionais para setores específicos. Como exemplos podem-se citar os cursos de Saúde Coletiva da ufba e de Economia da Saúde da Unifesp. E o terceiro modelo seria fruto de uma hibridização dos anteriores e consubstancia-se nos mestrados profissionais em ensino, voltados para a prática do profissional docente, como os cursos de Ensino das Ciências da ufrpe e Ensino de Física da ufrgs.

Outro ponto de discussão acerca dos mestrados profissionais é a questão do seu financiamento. Na visão de Ribeiro (2005), os MPs são governados, em grande medida, pela questão do financiamento, ou seja, devem buscar parcerias e convênios de forma a torná-los financeiramente viáveis, devem buscar patrocínios. O autor explica que tal orientação fundamenta-se no argumento de que os títulos acabam por agregar muito ao indivíduo e à organização que o emprega, não sendo justo que os cofres públicos os financiem. Ademais, ressalta-se que as universidades públicas não podem cobrar pelos seus cursos.

Fischer (20I0 questiona a razão pela qual os MPs não poderiam ser oferecidos pelas universidades públicas de forma gratuita, com financiamento similar ao acadêmico ou por fundos de pesquisas. Sem embargo, Ribeiro (2005) ressalta que o Conselho Nacional de Educação decidiu pela legalidade na obtenção de recursos por meio de fontes externas, onde não haveria cobrança direta do aluno. Assim, é totalmente lícito que uma organização patrocine um mestrado profissional, como é o caso da Embraer junto ao Instituto Tecnológico de Aeronáutica ou da Fiocruz em conjunto com a UFBA. Esse formato, ao mesmo tempo em que exige uma negociação em ampla escala, pode tornar o projeto do mestrado mais ambicioso. 


\section{DISTINÇÕES ENTRE O MESTRADO PROFISSIONAL E O ACADÊMICO}

Os cursos de mestrado acadêmico são os mais presentes no cenário brasileiro. Piquet, Leal e Terra (2005) destacam que a associação exagerada dos mestrados acadêmicos com o conhecimento e o ambiente da academia é um dos principais problemas para a aceitação dos MPs. Segundo estes autores, o sistema de pós-graduação brasileiro deveria ter sido revisto como um todo, incluindo a discussão sobre o mestrado em si. Isto poderia fazer com que a introdução da vertente profissional ocorresse de forma menos problemática.

Menandro (2010) destaca que a origem das discussões em torno dos mestrados, acadêmico e profissional, se deve a alguns pontos, a saber: a) uma possível ambiguidade associada ao termo inicial usado (profissionalizante), demasiadamente associado à graduação e ao ensino médio, o que causou certa preocupação dos acadêmicos em relação ao seu rigor; b) a divulgação inicial de que os MPs não permitiriam acesso ao doutorado, o que causou discussão pelo fato de ser uma pós-graduação stricto sensu; c) a falta de clareza na explicitação das diferenças entre os mestrados profissionais e os bons cursos de especialização, ainda existentes em algumas áreas; $d$ ) a um possível sentimento de traição por parte de alguns grupos da comunidade acadêmica pública e privada, ao ter conhecimento de que havia a possibilidade de inserção de professores não doutores nos MPs, num momento em que buscavam ampliar suas qualificações com vistas a abrir programas de mestrado acadêmico; e) à pouca exploração sobre o que seria aceito como trabalho final de curso; e f) ao termo autofinanciamento presente na portaria $n^{\circ}$. 47/I995, que reativou a discussão sobre a gratuidade do ensino público. Enfim, temia-se que estes cursos fossem na contramão da internacionalização dos cursos de mestrado acadêmico e doutorado, aceitando-se cursos de menor rigor acadêmico.

Fischer (2005) assevera que os MPs são cursos acadêmicos, uma vez que a grande maioria existe no ambiente da academia. Para a autora, a inércia estrutural do sistema de pós-graduação brasileiro, a hipervalorização dos mestrados acadêmicos e o esforço das áreas a serem conhecidas 
como produtoras de conhecimento científico criaram uma rejeição ao formato diferenciado proposto nos MPs.

Para Castro (2005), a estrutura dos MPs atrelada à dos mestrados acadêmicos lhes tira a personalidade e os coloca numa posição subalterna na pós-graduação stricto sensu. As exigências a serem cobradas pela Capes devem ser equivalentes às propostas dos MPs, prescindindo de comparabilidade com os cursos acadêmicos.

Os cursos de mestrado profissional e acadêmico são essencialmente diferentes em seus objetivos. O curso acadêmico visa à reprodução da instituição universitária, ou seja, a sua perpetuação ao longo do tempo, na medida em que forma professores pesquisadores. O curso profissional abre-se para setores mais amplos da sociedade, beneficiando-a e também as organizações nas quais os profissionais irão atuar (BERTERO, 1998; QUELHAS; FARIA FILHO; FRANÇA, 2005; VASCONCELOS; VASCONCELOS, 20IO).

De acordo com Ribeiro (2005), a principal diferença entre os mestrados acadêmicos e os profissionais está no resultado final almejado. Enquanto no programa acadêmico este culmina na formação do pesquisador, nos MPs o objetivo é formar um profissional capacitado para localizar, reconhecer, identificar e usar a pesquisa nas suas atividades. Assim, tal qual na formação acadêmica, a profissional não prescinde de imersão em pesquisa. E para que isso ocorra de forma satisfatória, a maior parte dos docentes precisa ser formada por professores doutores com produção científica constante.

Um mestrado profissional deve formar um mestre que não será classificado como um cientista ou um pesquisador tradicional. Será um profissional capacitado para saber localizar, reconhecer e usar a pesquisa de qualidade, calcado em bases acadêmicas, mas de cunho eminentemente prático (SCARANO; OLIVEIRA, 2005).

Para Ruas (2003), os mestrados profissionais tratam dos problemas das organizações, enquanto os programas acadêmicos partem dos problemas para discutir a problemática. Ou seja, priorizam a reflexão sobre a problemática geral do tema, envolvendo dimensões históricas, econômicas, sociais e políticas. E não tendo a preocupação com o problema numa perspectiva pragmática, também não têm compromisso com a busca de 
soluções. Os mestrados profissionais estimulam formas diferenciadas de pensar e atuar sobre o problema, envolvendo decisões em cenários que exigem deliberações sistêmicas rápidas sob incerteza, que são a realidade para boa parte das organizações.

Neste sentido, Virmond (2002) defende que os MPs, como formação terminal, são indicados para aqueles que desejam aprofundar a formação científica e profissional recebida nos cursos de graduação, mas que não têm interesse em atividades de pesquisa dentro do escopo dos programas de doutorado. Estes indivíduos, altamente capacitados, são absorvidos pelo mercado de trabalho profissional ou de educação, atuando como docentes em cursos profissionais e no ensino fundamental e médio.

O perfil dos alunos dos mestrados profissionais também é diferenciado. No geral são pessoas que buscam melhorar a qualificação profissional junto a um curso de excelência, em termos de conteúdo e forma, conciliando aulas e trabalho. Possuem experiência profissional considerável, além de participarem de diversos outros cursos e eventos e lerem revistas e livros especializados (FISCHER, 2003).

Com relação ao rigor dos mestrados profissionais e dos mestrados acadêmicos, Agopyan e Oliveira (2005) asseveram que não há motivo para entender o segundo como mais rigoroso em relação ao primeiro. A pesquisa para a inovação voltada para aplicação prática, um dos focos dos MPs, deve ser tão importante quanto a pesquisa desenvolvida nos programas acadêmicos. $\mathrm{O}$ mesmo deve ser entendido em relação à dedicação do aluno, à exigência de créditos e ao aprofundamento de temas. Ademais, a definição dos temas de pesquisa nos MPs deve acompanhar tanto as demandas empresariais, quanto as demandas sociais, haja vista ser um curso para profissionais em geral, tanto de organizações privadas, quanto de organizações públicas e sem fins lucrativos. O trabalho final, ao flexibilizar a proposta da tradicional dissertação, não se traduz em algo de menor rigor científico. O que muda é o foco, não o rigor.

Para Fischer (20I0), os MPs têm natureza e estruturas próprias e não devem ser referenciados pelos cursos do eixo acadêmico. Não quer dizer que têm menor qualidade, apenas são essencialmente diferentes e podem 
representar um componente importante de um fluxo entre graduação tecnológica e pós-graduação. Como defende Ribeiro (2006, alguns desafios do mestrado profissional são tão altos ou ainda maiores do que se postam nos programas acadêmicos.

Os mestrados profissionais ao mesmo tempo em que atendem a uma demanda latente ajudam, por outro lado, a melhor focalizar o mestrado acadêmico. O mestrado profissional tem a formação voltada para a prática profissional. $\mathrm{O}$ acadêmico, quando terminal, capacita para a docência superior, e, quando evolutivo, constitui-se numa etapa hierárquica, para o doutoramento e na formação do pesquisador, mesmo não sendo obrigatória, haja vista a possibilidade de doutorado direto (virmond, 2002).

Com relação à interdisciplinaridade, Feltes e Baltar (2005) argumentam que os MPs constituem-se num espaço adequado para o desenvolvimento de atividades e pesquisas de cunho inter e multidisciplinares. Isto porque no ambiente profissional o trânsito por diversos campos do conhecimento e suas interfaces é cada vez mais valorizado. Desse modo, a pesquisa formal pode ser entendida como uma atividade reflexiva crítica e inovadora, aplicada no âmbito das organizações, ou seja, nos seus problemas práticos.

Os MPs têm vocação interdisciplinar uma vez que abordam, na sua grande maioria, aspectos relacionados à gestão, escolha política, custo $\mathrm{e}$ benefícios sociais, além da transferência do conhecimento para a sociedade. Contudo, mesmo tendo vocação interdisciplinar, não significa que estes cursos devam ser avaliados somente como tal. Ribeiro (2005) assevera que os cursos devem ser avaliados na área mais próxima a ele e não somente na área Multidisciplinar da Capes.

\section{DISTINÇÕES ENTRE O MESTRADO PROFISSIONAL E A ESPECIALIZAÇÃO}

No início da implantação dos MPs, como discorre Piquet, Leal e Terra (2005), eles foram vistos como cursos de especialização com dissertação, como uma forma de tentar aumentar o valor dos primeiros em relação ao mercado. Mesmo havendo instituições que realmente buscaram este caminho, existem diferenças conceituais relevantes entre as modalidades de 
cursos. Ainda assim, diferenciar tais modalidades de cursos não tem sido uma tarefa fácil (IKEDA; CAMPOMAR; VELUDO-DE-OLIVEIRA).

Os cursos de pós-graduação lato sensu não têm a pretensão de propor um salto qualitativo na formação do estudante, pelo menos não como regra ou princípio, como afirma Ribeiro (2006). Correspondem a uma atualização, que pode ser repetida várias vezes ao longo da vida de um indivíduo, repetição esta que dificilmente ocorre na pós-graduação stricto sensu. Assim, o aluno não é formado, mas sim treinado ou informado. Neste sentido, o autor defende que todo e qualquer curso de atualização ou informação deva ficar fora do âmbito do stricto sensu. A fronteira é tênue, mas não inexistente. Nos MPs não se espera que o aluno atue como pesquisador, mas que saiba incorporar valores e práticas no seu ambiente de trabalho, tornando-o um usuário privilegiado da mesma.

Virmond (2002) assevera que os cursos de especialização objetivam a capacitação em um determinado ramo profissional ou científico, sem abranger o campo total do saber na área em que está inserido. Assim, formam um profissional especializado, com conhecimento técnico de uma limitada e certa área do saber ou da profissão. Ademais, possuem temporalidade espacial e liberalidade geográfica, como os cursos à distância, estando sujeitos às necessidades do momento e modificando-se em função da demanda. A especialização corresponde a um aprofundamento do conhecimento obtido na graduação, porém não com o rigor nem as disciplinas com forte conteúdo teórico-metodológico dos mestrados, profissional ou acadêmico.

Essa formação especializada em uma área citada, conforme Virmond (2002, é caracterizada por Quelhas, Faria Filho e França (2005, p. 98) como uma verticalização do conhecimento. Ao invés de buscarem a horizontalidade, ou seja, as fronteiras entre áreas de conhecimento, as especializações acabam por capacitar os profissionais para uma atuação profissional definida e bem circunscrita. Assim, não é de se estranhar que alguns profissionais façam mais de uma especialização.

Os cursos de especialização são focados em problemas práticos com vistas a aplicações imediatas de técnicas, ferramentas e soluções já sistematizadas, 
ou seja, "receitas de bolo". Assim, um curso de especialização dificilmente conseguiria dar tratamento em questões mais complexas, que envolvessem uma análise mais aprofundada de um tema (RUAS, 2003).

Wood Jr. e Paes de Paula (2004) destacam que especificamente os mestrados profissionais em Administração também diferem de forma significativa dos programas de мBA estrangeiros, constituindo "[...] modelo híbrido: não seguem completamente a tradição dos mBas norte-americanos, porém tampouco constituem transposições diretas dos mestrados acadêmicos e cursos de especialização que os precederam [...]”. Entre as tensões que diferenciam os cursos destacam-se: a) a ênfase na crítica e não na instrumentalização do conteúdo, como esperada por parte do alunado; b) exigência de grande dedicação ao programa, ante a limitação causada pelo vínculo empregatício do alunado; e c) demanda por formação docente ou empreendedora de alguns alunos, ante a formação voltada para a prática empresarial. Ademais, em pesquisa realizada concluíram que boa parte dos entrevistados, coordenadores de cursos de mestrado profissional em Administração, tem uma tendência à negação do rótulo de MBA. Isso ocorre porque no Brasil há uma disseminação do termo MBA tanto para cursos de especialização, quanto para cursos de educação executiva de curta duração (cursos livres para o MEC). Assim, os MPs brasileiros não podem ser entendidos nem como os mBAS americanos, tampouco como os cursos de especialização ou de mestrado acadêmico do Brasil. São, portanto, cursos híbridos, com características de cada um destes, porém com essência própria.

\section{O TRABALHO FINAL NOS MESTRADOS PROFISSIONAIS}

Não há razão para entender a dissertação do mestrado profissional como essencialmente diferente, em termos substantivos, de qualquer outra dissertação. Pode ser diferenciada em termos de forma ou estilo, em termos de coleta e análise de dados, "[...] mas se ajuda a fixar o 'saber como' e o 'saber por que' e a avaliar a compreensão do candidato sobre seu papel neste discurso crítico", será um trabalho final de curso válido, como qualquer outra dissertação (SPINK, I997, p. I64). 
Mattos (1997) assevera que os MPs possuem como característica intrínseca a necessidade de contribuição para o ambiente organizacional, baseada na pesquisa de soluções para um problema existente. Assim, um trabalho final construído dentro dos moldes da academia e que corresponde às expectativas da organização será perfeitamente aceitável. Com relação à qualidade, o principal critério de avaliação destes trabalhos deve ser a própria utilidade para a organização, ou seja, se a mesma o considera aplicável diretamente no seu processo decisório. Por se tratar de um programa cooperativo, não há como abdicar do crivo da empresa na avaliação dos trabalhos finais. Este é um dos pontos a serem revistos, além da participação das organizações no acompanhamento dos trabalhos e também nas bancas examinadores.

Os MPs devem ter um trabalho final de curso de rigor semelhante à dissertação dos mestrados acadêmicos. A mudança está na flexibilização do produto final. Um ponto questionado por alguns autores refere-se à avaliação deste produto final. Como se trata de um curso no qual os setores de produção estão envolvidos, estes deveriam compor a banca de avaliação (AGOPYAN; LOBO, 2007; MATTOS, I997).

Vasconcelos e Vasconcelos (20I0) argumentam que, em termos ideais, não deveria haver mestrado acadêmico, mas unicamente o profissional. Os que desejassem atuar como pesquisadores partiriam diretamente para o doutorado. Porém, tal visão é um tanto descontextualizada. O mestrado acadêmico é fundamental no momento atual do país, principalmente porque em algumas regiões do país não seria viável a instalação de um programa de doutorado. Ainda é necessária a formação de um corpo acadêmico produtivo para que os doutorados assumam, de forma exclusiva, a formação dos pesquisadores. As dimensões do país e o deficit educacional fazem com que a formação de mestres acadêmicos para a docência e pesquisa seja fundamental.

O Quadro 2 apresenta um comparativo dos diferentes tipos de cursos da pós-graduação brasileira em relação a algumas discussões apontadas na literatura. 
Quadro 2 Comparativo dos cursos presentes na pós-graduação brasileira

\begin{tabular}{|c|c|c|c|c|c|}
\hline \multirow{2}{*}{$\begin{array}{l}\text { Quesitos } \\
\text { presentes } \\
\text { na } \\
\text { literatura }\end{array}$} & \multicolumn{2}{|l|}{ Lato sensu } & \multicolumn{3}{|l|}{ Stricto Sensu } \\
\hline & Especialização & MBA & $\begin{array}{l}\text { Mestrado } \\
\text { Acadêmico }\end{array}$ & $\begin{array}{l}\text { Mestrado } \\
\text { Profissional }\end{array}$ & Doutorado \\
\hline Objetivos & $\begin{array}{l}\text { Atualização e } \\
\text { informação }\end{array}$ & $\begin{array}{l}\text { Aperfeiçoamento } \\
\text { de habilidades } \\
\text { pessoais e } \\
\text { gerenciais }\end{array}$ & $\begin{array}{l}\text { Formar } \\
\text { professores e } \\
\text { pesquisadores }\end{array}$ & $\begin{array}{l}\text { Formar } \\
\text { profissionais } \\
\text { de alto nível }\end{array}$ & $\begin{array}{l}\text { Formar pes- } \\
\text { quisadores } \\
\text { seniores }\end{array}$ \\
\hline $\begin{array}{l}\text { Público- } \\
\text { alvo }\end{array}$ & $\begin{array}{l}\text { Graduados em } \\
\text { geral }\end{array}$ & $\begin{array}{l}\text { Graduados em } \\
\text { geral }\end{array}$ & $\begin{array}{l}\text { Graduados em } \\
\text { geral }\end{array}$ & $\begin{array}{l}\text { Graduados } \\
\text { em geral, com } \\
\text { experiência } \\
\text { profissional }\end{array}$ & $\begin{array}{l}\text { Mestres ou } \\
\text { graduados }\end{array}$ \\
\hline $\begin{array}{l}\text { Duração } \\
\text { mínima } \\
\text { (legal) }\end{array}$ & 360 horas & 360 horas & 1 ano & 1 ano & 2 anos \\
\hline $\begin{array}{l}\text { Duração } \\
\text { (mais } \\
\text { frequente) }\end{array}$ & 360 horas & 360 horas & 2 anos & 2 anos & 4 anos \\
\hline $\begin{array}{l}\text { Corpo } \\
\text { docente } \\
\text { (legal) }\end{array}$ & $\begin{array}{l}\text { Especialistas, } \\
\text { mestres e } \\
\text { doutores }\end{array}$ & $\begin{array}{l}\text { Especialistas, } \\
\text { mestres e doutores }\end{array}$ & Doutores & $\begin{array}{l}\text { Doutores e } \\
\text { profissionais } \\
\text { (experiência } \\
\text { consolidada) }\end{array}$ & Doutores \\
\hline $\begin{array}{l}\text { Título } \\
\text { recebido } \\
\text { (legal) }\end{array}$ & Especialista & Especialista & Mestre & Mestre & Doutor \\
\hline $\begin{array}{l}\text { Trabalho de } \\
\text { conclusão } \\
\text { (legal) }\end{array}$ & $\begin{array}{l}\text { Monografia } \\
\text { ou Trabalho de } \\
\text { Conclusão de } \\
\text { Curso }\end{array}$ & $\begin{array}{l}\text { Monografia } \\
\text { ou Trabalho de } \\
\text { Conclusão de } \\
\text { Curso }\end{array}$ & Dissertação & $\begin{array}{l}\text { Dissertação ou } \\
\text { outras formas } \\
\text { de trabalho } \\
\text { final }\end{array}$ & Tese \\
\hline $\begin{array}{l}\text { Autorização } \\
\text { para início }\end{array}$ & Não necessária & Não necessária & $\begin{array}{l}\text { Necessária } \\
\text { (Capes) }\end{array}$ & $\begin{array}{l}\text { Necessária } \\
\text { (Capes) }\end{array}$ & $\begin{array}{l}\text { Necessária } \\
\text { (Capes) }\end{array}$ \\
\hline $\begin{array}{l}\text { Avaliação } \\
\text { formal }\end{array}$ & $\begin{array}{l}\text { Supervisão no } \\
\text { recredenciamento } \\
\text { da IES }\end{array}$ & $\begin{array}{l}\text { Supervisão no } \\
\text { recredenciamento } \\
\text { da IES }\end{array}$ & $\begin{array}{l}\text { Realizada pela } \\
\text { Capes }\end{array}$ & $\begin{array}{l}\text { Realizada pela } \\
\text { Capes }\end{array}$ & $\begin{array}{l}\text { Realizada } \\
\text { pela Capes }\end{array}$ \\
\hline
\end{tabular}

Fonte: Adaptado de Giuliani et al. (2007).

\section{EXPERIÊNCIAS DE MESTRADOS PROFISSIONAIS RELATADAS NA LITERATURA ACADÊMICA}

Dourado (2005) relata a experiência do mestrado profissional em Saúde Coletiva desenvolvido na UFBA. O curso representa uma formação pósgraduada que objetiva formar dirigentes e técnicos no âmbito do Sistema 
Único de Saúde (sus) com a finalidade de elevar a qualidade da sua gestão, planejamento, organização e operacionalização dos serviços. O curso apresenta um desenho curricular inovador, sob a forma de módulos, oficinas de trabalho e supervisão à distância, intercalados por orientação presencial. A prática de investigação é realizada no ambiente profissional do aluno, ou seja, na instituição de origem, visando os problemas do cotidiano institucional, e desenvolvida ao longo de doze meses sob orientação dos professores do programa. Os produtos finais desenvolvidos pelos alunos, na forma de tecnologias, manuais, instrumentos de triagem, diagnósticos de saúde e projetos de intervenção contribuem para o aperfeiçoamento das práticas, ao mesmo tempo em que agregam conhecimento à área e auxiliam no desenvolvimento do SUS. O financiamento feito por meio de convênios entre a universidade e as instituições patrocinadoras (com o Ministério Público, com a Secretaria Estadual de Saúde Bahia ou com a Agência de Vigilância em Saúde, por exemplo) tem beneficiado o programa de pósgraduação, principalmente no que tange à sua infraestrutura administrativa. E os editais do curso, apesar de direcionados a clientelas específicas, foram, e na visão da autora devem sê-lo, abertos a todos que atendiam aos requisitos.

Em pesquisa realizada junto aos alunos do mestrado acadêmico em Administração da Universidade de São Paulo (USP), Gouvêa e Zwicker (2000) evidenciaram uma mudança no perfil dos novos matriculados, sendo marcante e crescente a presença de pessoas que não atuam na docência. Assim, os autores argumentam que outra opção de curso para este perfil de aluno permitiria dar ao mestrado acadêmico um viés mais voltado para o ensino e a pesquisa, visto que o programa atual incorpora características profissionais, sendo justamente por isso, procurado cada vez mais por este público. Dessa forma, os MPs poderiam trazer um duplo benefício à instituição: capacitar alunos com perfil profissional e enquadrar corretamente o mestrado acadêmico.

Ruas (2003), após pesquisa realizada com egressos do MP em Administração da UFRGS, destacou quatro pontos ressaltados pelos alunos como principais contribuições do curso. O primeiro deles refere-se à maior confiança e segurança para atuar em ambientes complexos e interdisciplinares. Uma 
segunda contribuição citada está relacionada à formação da rede de relacionamento, principalmente por se tratar de profissionais com carreiras mais estabelecidas, o que permitiu a construção de diferentes visões de mundo, mais heterogêneas e, consequentemente, complexas. A terceira refere-se à maior capacidade de analisar mais profundamente os cenários e as situações, grande parte de origem e natureza diferentes, do mundo real. E, por fim, o aprendizado de métodos mais sistemáticos para a resolução de problemas, ou seja, o aprendizado metodológico.

Em pesquisa realizada junto ao mestrado profissional em Administração da UFBA, Andrade, D’Ávila e Oliveira (2004) analisaram o perfil dos alunos, dos docentes e a percepção destes em relação às especificidades dos MPs. Com relação ao corpo discente, verificou-se uma maior quantidade de pessoas do sexo masculino (70\%), com média de idade entre 35 e 45 anos, superior à média do mestrado acadêmico, com formação profissional diversificada e predominância de engenheiros (50\%), oriundos de diferentes setores da economia, situados em postos relativamente altos nas suas organizações e tendo a maioria mais de dez anos de experiência. Em relação ao perfil do corpo docente, a maioria são doutores $(90 \%)$ com formação e doutoramento em áreas diversificadas e que possuem atividades fora da academia, como executivos, pesquisadores ou consultores. Ademais, o curso conta com professores convidados de outras unidades da própria universidade e de outros programas de pós-graduação nacionais e internacionais. E, em relação à percepção dos professores sobre as especificidades do curso, os dados coletados indicaram que a maioria tem clareza quanto às características de um curso com viés profissional e necessidade de integração entre a teoria e a prática. Sobre a relação entre teoria e prática, os autores ressaltam a fala de um professor, o qual destaca que tal integração não deve se dar pela concessão de instrumentos e ferramentas, mas por meio da reflexão sobre os princípios teóricos.

Barros (2008) relata a experiência do mestrado profissional em Desenvolvimento Sustentável da Universidade de Brasília. O curso, que fora impulsionado inicialmente pela Capes, CNPq e IBAMA, para qualificar seus quadros funcionais, compõe o Programa de Pós-Graduação em 
Desenvolvimento Sustentável, junto com o curso de mestrado acadêmico. Os cursos possuem currículos semelhantes, existindo disciplinas idênticas em um curso e noutro, mantendo a conexão com o objeto dos mesmos. Tanto o mestrado acadêmico quanto o profissional exigem uma defesa de dissertação como trabalho final, ainda que a legislação tenha flexibilizado o produto dos MPs. Destaca-se que curso tem características de interdisciplinaridade, congregando profissionais com formação em áreas do conhecimento bem diversas, o que contribui para a interdisciplinaridade.

As experiências de três cursos da área de Engenharia Mecânica são relatadas por Passos, Gerges e Cunha Neto (2006); são eles: o mestrado profissional em ruídos e vibrações (parceria com a Fiat), em engenharia mecânica (parceria com o Senai/Cimatec e a Braskem) e em projeto mecânico de motores elétricos (parceria com a WEG Motores), todos ofertados pela Universidade Federal de Santa Catarina (UFSC). Os cursos foram concebidos para ser ministrados fora da sede da universidade, para profissionais de empresas patrocinadoras, em horários flexíveis, com uso de novas tecnologias e com desenvolvimento de trabalho final em laboratórios de empresas ou outras instituições de ensino parceiras, sempre tendo como enfoque principal problemas do setor produtivo. Entre os benefícios para as organizações parceiras destacam-se: a) formação dos quadros sem a necessidade de afastamento do trabalho; b) investigações sempre aplicadas, impactando em redução de custos na maioria dos casos; c) investigações que tivessem resultado no desenvolvimento de novos processos; d) suporte técnico e científico; e) desenvolvimento de pesquisas pré-competitivas, que culminam em maior competitividade. Os benefícios para o programa são: a) envolvimento dos professores com problemas práticos; b) desenvolvimento de pesquisas com forte viés aplicado; c) cooperação entre os laboratórios das instituições parceiras; d) aumento do número de mestres formados; e) obtenção de patrocínio do setor privado; e f) realização de novas parcerias. Os autores destacam ainda que os problemas trazidos pelo setor produtivo são, geralmente, de alta complexidade, envolvendo tratamento multidisciplinar e que não podem prescindir de forte base teórica. 
Saupe e Wendhausen (2006) abordam a questão dos trabalhos finais de curso nos MPs, especificamente no mestrado profissional interdisciplinar em saúde e gestão do trabalho, da Universidade do Vale do Itajaí (Univali). As autoras relatam o uso de uma abordagem matricial para a construção do conhecimento, na qual cada professor orientador coordena um projeto integrado, vinculado à sua linha de pesquisa. Os projetos são desdobrados em subprojetos e esse processo permite o aprofundamento na compreensão dos temas estudados, ao mesmo tempo em que agregam pesquisadores experientes e iniciantes. Para as autoras, o modelo matricial possibilita a multiplicidade de enfoques, ou seja, a multi e interdisciplinaridade, características dos MPs, permitindo a triangulação de dados, pesquisadores, teoria e métodos. Ao mesmo tempo, resulta em trabalhos finais compromissados com uma contribuição real para a prática, uma das principais preocupações do programa.

Uma análise dos cenários futuros da pós-graduação da Escola Nacional de Saúde Pública, vinculada à Fundação Oswaldo Cruz (Fiocruz), foi realizada por Freitas e outros (2006). Os resultados permitiram concluir que os MPs são de suma importância para a referida escola e também para a área de Saúde Coletiva por: a) permitir distinguir de forma mais eficaz a formação para docência e pesquisa (mestrado acadêmico e doutorado) e a formação de profissionais qualificados com atuação no sus; e b) ser um elo entre os cursos stricto sensu e lato sensu, o que permite articular diferentes níveis na formação de quadros estratégicos para a área de saúde, especificamente de profissionais indutores de processos de mudanças em seus ambientes de trabalho, mediante a adoção de novas práticas e o desenvolvimento de novos produtos.

O mestrado profissional em ensino teve uma de suas experiências relatada por Araújo e Amaral (2006). O programa abordado foi de Ensino de Ciências e Matemática, da Universidade Cruzeiro do Sul (Unicsul), cujo objetivo é a formação de profissionais qualificados para atuar prioritariamente no ensino fundamental e no ensino médio. A pesquisa dos autores envolveu, entre outros pontos, as contribuições do mestrado profissional para sua atividade docente, o impulso no desenvolvimento de valores e atitudes, proporcionado 
pelo programa e pelas novas perspectivas de desenvolvimento profissional após o término do curso. Com relação às contribuições, o desenvolvimento de ações baseadas em uma visão mais ampla e reflexiva sobre os processos de ensino e aprendizagem foram destaque, e as condições promovidas pelo programa para o uso de novas metodologias e estratégias de ensino e a ampliação e atualização de conhecimentos foram as mais citadas pelos respondentes. No que tange ao desenvolvimento de valores e atitudes, os relatos ressaltam a melhora na postura crítica e reflexiva em relação à atuação docente e a possibilidade de atuação em pesquisas, o que poderia contribuir para a atuação na docência. E, com relação às novas perspectivas após o término do curso, os resultados indicam dois pontos principais: a) o desenvolvimento das atividades profissionais com mais eficiência, autonomia, capacidade de reflexão e relacionamento colaborativo com outros docentes; e b) possibilidade de atuação em outros espaços de trabalho, notadamente em instituições de ensino superior. 


\section{CONSIDERAÇÕES FINAIS}

O surgimento de um novo formato educacional traz consigo muitas indagações e poucas certezas. Mesmo nos formatos estabelecidos há décadas é normal que discussões acaloradas sejam iniciadas (vasCONCELOS; vasConcelos, 20IO). Assim acontece com os MPs, por representarem um novo formato, ao mesmo tempo em que trazem discussões sobre o formato estabelecido.

A introdução dos MPs no ambiente acadêmico brasileiro não ocorreu de forma branda. Silveira e Pinto (2005) destacam que poucas discussões têm causado maior polêmica do que às relativas aos MPs. Fischer (2010) assevera que a polêmica se dá por conta do fomento de novos cursos de MPs, por parte do Ministério da Educação, por meio da Capes e do Conselho Nacional de Educação, e pela comunidade acadêmica, que se mantêm divididos entre as áreas que oferecem MPs e as que reagem a ele. Para Piquet, Leal e Terra (2005) parte da comunidade acadêmica rejeitou (e ainda rejeita) os MPs, considerando-os como cursos de "segunda linha", mesmo pouco conhecendo as suas especificidades. Existe ainda, por parte das instituições, como destaca Virmond (2002), uma falsa percepção de que o mestrado profissional pode desaboná-las e que apenas os programas acadêmicos dão prestígio e promovem a qualificação da universidade, o que representa um equívoco.

Os MPs representam uma reconstrução da pós-graduação como uma estratégia para atendimentos dos setores profissionais. Como toda proposta inovadora, apesar de já constar na legislação há bastante tempo e de os primeiros cursos já terem mais de dez anos, trazem consigo os elementos de sedução e risco. Sedução por conta dos novos modelos curriculares, da mescla do quadro docente, com profissionais e professores doutores, das articulações necessárias entre teoria e prática e da conciliação dos estudos com o trabalho. Risco por conta da proposta de conciliar os contrários, os eixos acadêmico e profissional (FISCHER, 2003; FISCHER, 20I0). Os MPs enfrentam um sistema institucionalizado, voltado para a formação de professores e para a pesquisa acadêmica. Dessa forma, caminha-se numa 
arena de interesses em meio a currículos e projetos pedagógicos, em meio a embates entre a docência e a consultoria, entre comunidades acadêmicas, e entre estas e agências reguladoras, onde:

[...] a prática acadêmica é o desafio. Imaginar, criar e desenvolver cursos inovadores em sistema fortemente regulado, com fortes componentes isomórficos com as áreas tradicionais de ciência (que são o paradigma para todas as demais) se constitui de fato em grande desafio (FISCHER, 20IO, p. 354). Enfim, é necessário aprender ainda mais sobre os MPs e sobre a sua identidade, de forma a entender suas especificidades e relações com os demais programas de formação, notadamente os cursos de pós-graduação (RUAS, 2003). Neste sentido, este artigo apresenta-se como uma contribuição para um entendimento adequado da proposta de um mestrado profissional e seus valores, bem identificados na sessão de experiências relatadas na literatura. 


\section{REFERÊNCIAS}

AGOPYAN, V.; OLIVEIRA, J. F. G. Mestrado profissional em engenharia: uma oportunidade para incrementar a inovação colaborativa entre universidades e os setores de produção no Brasil. Revista Brasileira de Pós-Graduação, v. 2, n. 4, p. 78-89, 2005.

AGOPYAN, V.; LOBO, R. O futuro do mestrado profissional. Revista Brasileira de PósGraduação, v. 4, n. 8, p. 293-302, 2007.

ANDRADE, C.; D’ÁVILA, C.; OLIVEIRA, F. Um olhar sobre a práxis pedagógica do mestrado profissional em Administração da Universidade Federal da Bahia. Revista Brasileira de Pós-Graduação, v. 1, n. 2, p. 81-96, 2004.

ARAÚJO, M. S. T.; AMARAL, L. H. Impactos do mestrado profissional em ensino de ciências e matemática da Unicsul sobre a atividade docente de seus estudantes: do processo de reflexão às transformações na prática pedagógica. Revista Brasileira de PósGraduação, v. 3, n. 5, p. 150-166, 2006.

BARROS, L. V. Notas sobre o mestrado profissionalizante: a experiência do Centro de Desenvolvimento sustentável da UnB. Revista Brasileira de Pós-Graduação, v. 5, n. 10, p. 353-364, 2008.

BARROS, E. C.; VALENTIM, M. C.; MELO, M. A. A. O debate sobre o mestrado profissional na Capes: trajetória e definições. Revista Brasileira de Pós-Graduação, v. 2, n. 4, p. 124-138, 2005.

BERTERO, C. O. Teses em mestrados profissionais. Revista de Administração Contemporânea, v. 2, n. 1, p. 165-172, 1998.

BRASIL. Parecer n ${ }^{\circ} 977$ CES, de 03 de dezembro de 1965. Dispõe sobre a definição dos cursos de pós-graduação. Disponível em: <http://www.fnmp.org.br/documentos/ parecer-977-ces-newton-sucupira/>. Acesso em: 18/06/2010.

BRASIL. Organização da educação superior, 2004. Disponível em: <www.mec.gov.br>. Acesso em: 02/04/2010.

BRASIL. Portaria n 47, de 17 de outubro de 1995. Determina a implantação na Capes de procedimentos apropriados à recomendação, acompanhamento e avaliação de cursos de mestrado profissional. Disponível em: <http://www.fnmp.org.br/documentos/ portaria-no-47-17-outubro-1995.pdf/>. Acesso em: 18/06/2010.

BRASIL. Portaria no 80, de 16 de dezembro de 1998. Dispõe sobre o reconhecimento dos mestrados profissionais e dá outras providências. Disponível em: $<$ http://www.fnmp. org.br/documentos/portaria-no-47-17-outubro-1995.pdf/>. Acesso em: 18/06/2010.

BRASIL. Portaria Normativa $n^{\circ}$ 7, de 22 de junho de 2009a. Dispõe sobre o mestrado profissional no âmbito da Fundação Coordenação de Aperfeiçoamento de Pessoa de Nível Superior - CAPES. Disponível em: <http://www.fnmp.org.br/documentos/ portaria-normativa-mec-n07-22-06-2009/>. Acesso em: 18/06/2010. 
BRASIL. Portaria Normativa $n^{\circ} 17$, de 28 de dezembro de 2009b. Dispõe sobre o mestrado profissional no âmbito da Fundação Coordenação de Aperfeiçoamento de Pessoa de Nível Superior - CAPES. Disponível em: < http://www.fnmp.org.br/documentos/ portaria-normativa-mec-n17-28-12-2009.pdf $>$. Acesso em: 18/06/2010.

CASTRO, C. M. A hora do mestrado profissional. Revista Brasileira de Pós-Graduação, v. 2, n. 4, p. 16-23, 2005.

DOURADO, I. Mestrado profissional em saúde coletiva: uma proposta alternativa para a qualificação de dirigentes e técnicos em saúde - Instituto de Saúde Coletiva da UFBA (2001-2005). Revista Brasileira de Pós-Graduação, v. 2, n. 4, p. 61-71, 2005.

FELTES, H. P. M.; BALTAR, M. A. R. Novas perspectivas para mestrados profissionais: competências profissionais e mercados regionais. Revista Brasileira de Pós-Graduação, v. 2, n. 4, p. 72-78, 2005.

FISCHER, T. Seduções e riscos: a experiência do mestrado profissional. Revista de Administração de Empresas, v. 43, n. 2, p. 119-123, 2003.

FISCHER, T. Mestrado profissional como prática acadêmica. Revista Brasileira de PósGraduação, v. 2, n. 4, p. 24-29, 2005.

FISCHER, T. Sobre a maestria, profissionalização e artesanato intelectual. Revista de Administração Contemporânea, v. 14, n. 2, p. 353-359, 2010.

FREITAS, C. M. de; RIVERA, F. J. U. R.; ARTMANN, E.; SANTOS, R.V. O mestrado profissional nos cenários futuros da Escola Nacional de Saúde Pública, Fundação Oswaldo Cruz. Revista Brasileira de Pós-Graduação, v. 3, n. 5, p. 129-149, 2006.

GIULIANI, A. C.; NOVAES NETTO, A. F. de; PONCHIO, M. C.; SACOMANO NETO, M.; BATISTA, C. M. MBAs, mestrados acadêmicos, mestrados profissionais e doutorados em administração: suas contribuições para o ensino e a pesquisa. Revista de Administração da Unimep, v. 5, n. 1, p. 52-73, 2007.

GOUVÊA, M. A.; ZWICKER, R. O mestrado profissionalizante e o perfil dos alunos de um mestrado acadêmico: resultados de uma pesquisa empírica. Caderno de Pesquisas em Administração, v. 7, n. 3, p. 99-110, 2000.

IKEDA, A. A.; CAMPOMAR, M. C.; VELUDO-DE-OLIVEIRA, T. M. A pós-graduação em Administração no Brasil: definições e esclarecimentos. Revista Gestão e Planejamento, v. 6, n. 12, p. 33-41, 2005.

KRIEGER, E.; GALEMBECK, F. A capacitação brasileira para a pesquisa. In: SCHWARTZMAN, S.; KRIEGER, E.; GALEMBECK, F.; GUIMARÃES, E. A.; BERTERO, C. O. (Orgs.). Ciência e tecnologia no Brasil: a capacitação brasileira para a pesquisa científica e tecnológica. Rio de Janeiro: Fundação Getúlio Vargas, 1996.

MATTOS, P. L. Dissertações não-acadêmicas em mestrados profissionais: isso é possível? Revista de Administração Contemporânea, v. 1, n. 2, p. 153-171, 1997.

MELO, K. V. A.; OLIVEIRA, R. R. Origens e desenvolvimento institucional de um mestrado profissional. Revista Brasileira de Pós-Graduação, v. 2, n. 4, p. 105-123, 2005. 
MENANDRO, P. R. M. Mestrado Profissional, você sabe com quem está falando? Revista de Administração Contemporânea, v. 14, n. 2, p. 367-371, 2010.

MOREIRA, M. L.; VELHO, L. Pós-Graduação no Brasil: da concepção "ofertista linear" para "novos modos de produção do conhecimento" implicações para avaliação. Avaliação (Campinas), v. 13, n. 3, p. 625-645, 2008.

NEGRET, F. A identidade e a importância dos mestrados profissionais no Brasil e algumas considerações para sua avaliação. Revista Brasileira de Pós-Graduação, v. 5, n. 10, p. 217-225, 2008.

PASSOS, J. C.; GERGES, S. N. Y.; CUNHA NETO, J. A. B. Três experiências do mestrado profissional em Engenharia Mecânica na UFSC. Revista Brasileira de PósGraduação, v. 3, n. 5, p. 117-128, 2006.

PIQUET, R.; LEAL, J. A. A.; TERRA, D. C. T. Mestrado profissional: proposta polêmica no Sistema Brasileiro de Pós-Graduação - o caso do planejamento regional e urbano. Revista Brasileira de Pós-Graduação, v. 2, n. 4, p. 30-37, 2005.

QUELHAS, O. L. G.; FARIA FILHO, J. R.; FRANÇA, S. L. B. O mestrado profissional no contexto do sistema de pós-graduação brasileiro. Revista Brasileira de Pós-Graduação, v. 2, n. 4, p. 97-104, 2005.

RIBEIRO, R. J. O mestrado profissional na política atual da Capes. Revista Brasileira de Pós-Graduação, v. 2, n. 4, p. 08-15, 2005.

RIBEIRO, R. J. Ainda sobre o mestrado profissional. Revista Brasileira de Pós-Graduação, v. 3, n. 6, p. 313-315, 2006.

RUAS, R. Mestrado modalidade profissional: em busca da identidade. Revista de Administração de Empresas, v. 43, n. 2, p. 55-63, 2003.

SAUPE, R.; WENDHAUSEN, A. L. P. Modelo matricial para construção de conhecimento no mestrado profissional em saúde. Revista Brasileira de Pós-Graduação, v. 3, n. 5, p. 107-116, 2006.

SCARANO, F. R.; OLIVEIRA, P. E. A. M. Sobre a importância da criação de mestrados profissionais na área de ecologia e meio ambiente. Revista Brasileira de Pós-Graduação, v. 2, n. 4, p. 90-96, 2005.

SCHWARTZMAN, S. A pesquisa científica e o interesse público. Revista Brasileira de Inovação, v. 1, n. 2, p. 361-395, 2002.

SILVEIRA, V. O.; PINTO, F. C. S. Reflexões necessárias sobre o mestrado profissional. Revista Brasileira de Pós-Graduação, v. 2, n. 4, p. 38-47, 2005.

SPINK, P. A formação acadêmica e a ciência: ampliando o debate sobre o mestrado profissional. Revista de Administração Contemporânea, v. 1, n. 3, p. 163-169, 1997.

VASCONCELOS, F. C.; VASCONCELOS, I. F. G. As dimensões e desafios do mestrado profissional. Revista de Administração Contemporânea, v. 14, n. 2, p. 360-366, 2010. 
VIRMOND, M. Mestrado profissional - uma síntese. Salusvita, v. 21, n. 2, p. 117-130, 2002.

WOOD JR., T.; PAES DE PAULA, A. P. O fenômeno dos MPAs brasileiros: hibridismo, diversidade e tensões. Revista de Administração de Empresas, v. 44, n. 1, p. 116-129, 2004. 


\section{DADOS DOS AUTORES}

\section{ROBERTO BRAZILEIRO PAIXÃO^ robertobrazileiro@gmail.com}

Doutor em Administração pela UFBA

Instituição de vinculação: Universidade Federal da Bahia

Salvador/BA - Brasil

Áreas de interesse em pesquisa: Avaliação educacional, avaliação institucional e gestão de IES.

* Escola de Administração da Universidade Federal da Bahia, NPGA - $3^{\circ}$ andar

Av. Reitor Miguel Calmon, $s / n \quad$ Canela Salvador/BA 40110-903

\section{ADRIANO LEAL BRUNI albruni@ufba.br}

Doutor em Administração pela USP

Instituição de vinculação: Universidade Federal da Bahia

Salvador/BA - Brasil

Áreas de interesse em pesquisa: Ensino de Contabilidade e Administração e Finanças. 